Stoa

Vol. 8 , no. 16,2017 , pp. $63-77$

ISSN 2007-1868

\title{
RACIONALIDAD PRÁCTICA: PHRONĒSIS Y SINDÉRESIS PARA UNA TEORÍA DE LA DECISIÓN MORAL
}

\author{
FABio Morandín \\ Instituto de Filosofía \\ Universidad Veracruzana
}

RESUMEN: En el presente artículo se contrastan los conceptos de prudencia y sindéresis, el primero desde la óptica aristotélica y el segundo desde la Escuela de París. Se define a la prudencia como el método para alcanzar los fines que se desean y a la sindéresis como la capacidad natural para juzgar de manera recta. Si bien se ha pensado que son dos conceptos inequiparables,

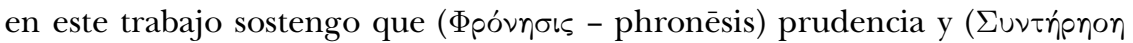
- syndêrêsis) sindéresis son dos momentos que forma parte de una teoría de la decisión, con la salvedad de que existen elementos racionales que se implican en la deliberación moral, pero, sobre todo, que es producto de una deliberación intuitiva de la persona, basada en los primeros principios.

PAlABRAS GLAVE: Prudencia - sindéresis · teoría de la decisión · ética aristotélica

ABSTRACT: In this article the concepts of prudence and synderesis are contrasted, the first from the Aristotelian point of view and the second from the School of Paris. Prudence is defined as the method for achieving the desired ends and synderesis as the natural ability to judge rightly. Although it has been thought that they are two concepts unequipable, in this work I argue

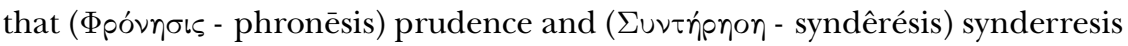
are two moments which are part of a theory of decision, with the condition that there are rational elements involved in moral deliberation, but, mostly, that is the product of an intuitive deliberation of person, based on first principles.

KEYWORDs: Prudence · Syderesis - Theory of Decision · Aristotelic Ethics 


\section{Introducción}

Todos los días el hombre se enfrenta a diversas decisiones, desde qué ropa usará o si debe tomar el camino más corto a su trabajo o el que probablemente tenga menos tráfico, hasta decisiones que tienen mayores consecuencias, aunque sean inmediatas. Estas son decisiones hasta cierto punto, sencillas, y se está en permanente deliberación sobre una u otra cosa decenas de veces en un solo día. Sabemos que no todas las decisiones son de la clase 1 o 2 , sino que pueden existir $n$ posibilidades, algunas están abiertas a un número indeterminado de probables elecciones. A mayor número de variables, la tensión por escoger se eleva por la incertidumbre del resultado. Sin embargo, hay otro tipo de decisiones que tienen que ver con el mediano y largo plazo, decisiones como: ¿Qué profesión se quiere tener? ¿Casarse o no casarse? ¿Cuáles son las metas principales que se quieren fijar en la vida? En fin, una serie de interrogantes que se pueden o no plantear de manera explícita.

Si bien hay quienes niegan que la idea de la sindéresis estuviera presente en la Grecia antigüa -"En la exposición de este tema central de la ética no podremos para nada recurrir a los griegos. El mundo indoeuropeo, encerrado en una Totalidad irrebasable, no podía escuchar una voz, un llamado (vocatio) que interrumpiera interpelante desde afuera" (Dussel, 1973) - en este breve artículo, sostendré que algunos conceptos presinderéticos ya se encuentran en la frónesis aristotélica y que Tomás de Aquino desarrolla en la Suma de Teología, como parte inherente a la deliberación moral a través de la razón práctica.

\section{Elección racional versus impulso}

Aristóteles analizó cuáles son las cosas sobre las que realmente se debe deliberar y cuándo es el caso en que realmente existe elección, esto es, una decisión para la acción como producto de la deliberación (voluntaria). Pero no podemos hablar de elección cuando son los impulsos los que llevan a la persona a optar por una opción por encima de otra. Esto es, el primer elemento para que exista elección es que debe existir una deliberación racional previa por encima del dictado de los impulsos (Cfr. EN, 1111b).

Para explicar un poco más lo anterior, Aristóteles hace la distinción entre lo que es voluntario e involuntario: Porque lo voluntario lo encontramos en los animales también, pero que sea voluntario no significa que sea producto de una elección ya que, para tomar una elección, se requiere de un proceso racional que en los seres irracionales (entendida como razonamiento práctico) es inexistente $(C f r . \mathrm{EN}, 1111 \mathrm{~b}){ }^{1}$

${ }^{1}$ Se podría poner en consideración esta idea de moral en los animales, para eso recomiendo el texto de Rowlands, M. 2012, ¿̈Pueden tener moral los animales?, Oxford University Press, Oxford. 
Tanto los animales como las persona incontinentes ${ }^{2}$ actúan según sus apetitos, y considera el estagirita que al carecer del proceso de racionalización de sus elecciones, actúan únicamente por impulso. La elección puede estar sobre el apetito, esto es, se puede tomar una elección dolosa, que, si bien vaya en contra de los apetitos, sea, por elección, a primera vista, desagradable, pero busque un fin ulterior mejor, que seguir los impulsos inmediatos. Vgr. Cuando alguien decide ponerse en régimen alimentario, podría sentir una fuerte inclinación a continuar con sus hábitos, mismos que podrían estarle perturbando su salud, pero por una elección racional y voluntaria, se anteponga ante el impulso a comer; así, de manera racional y con un carácter fortalecido, tomar la decisión de controlar ese impulso y renunciar a continuar con ese hábito. Es lo que se llama fuerza de voluntad. ${ }^{3}$

Dice Aristóteles que a los apetitos no pueden oponerse los apetitos, sólo la elección (EN, 1112a 13). En el impulso, entonces, no hay elección. Es una fuerza mayor que conduce a la persona a actuar bajo la égida de sus necesidades básicas. Por ejemplo, advertimos que comer es una necesidad de toda persona para poder mantener el equilibrio homeostático, pero no es necesario comer en exceso. Aunque algunas personas requieran de una gran cantidad de comida para mantener el equilibrio entre calorías demandantes y sensación de saciedad, ello no significa que su cuerpo necesite de esa gran cantidad de calorías para poder vivir, por el contrario, podría ser que para tener un verdadero equilibrio homeostático, y sobre todo, salud, requiera sólo de la cuarta parte de calorías que comúnmente consuma. Si bien su cerebro, su lengua y su estómago se lo demandan no significa que lo necesite para mantenerse vivo. ${ }^{4}$

\section{Posibilidad}

Por otra parte, la elección, para que sea genuina, Aristóteles considera que debe ser posible porque no podemos elegir algo imposible y da el ejemplo

${ }^{2}$ Aristóteles llama así a quienes se dejan dominar por sus apetitos.

${ }^{3}$ Según Aristóteles lo que se hace impulsivamente no puede considerarse una elección, aunque no estamos del todo de acuerdo con esa afirmación, porque, aún cuando se actúa de manera impulsiva, existe un momento previo para la elección. Vgr. Si bien se puede argumentar que el morfinómano no puede contener sus ansías por consumir la droga debido a la dependencia física y psíquica, la elección previa se dio cuando decidió, por vez primera, probar con una inyección y luego otra, y otra. Cuando su cerebro le exige una nueva dosis, es, en realidad, él mismo quien se ha puesto en esa posición por elección. Es muy improbable que alguien le haya apuntado con una pistola en la cabeza para consumir la droga, sin embargo, después, la dependencia física, es tan grande que pareciera como si tuviera una pistola imaginaria en la cabeza que lo obliga, por impulso, a consumir dicha sustancia.

${ }^{4}$ Puede encontrarse una explicación a esto en Damasio, A. 2010, Y el cerebro creó al hombre, Destino, Madrid. Los mapas interoceptivos, explica, son los mecanismos a través de los cuales el cerebro busca la homeostásis y manda señales para la acción. Mapas que informan a la persona sobre el estado de sus órganos con la finalidad de gestionar y controlar de modo eficiente los procesos de la vida orgánica (Cfr. Cap. 3). 
de la inmortalidad (EN, 1112a, 20-25). Cualquiera podría escoger ser inmortal, pero ello no significa que sea posible. Entonces no puede existir de una verdadera elección, dice el autor griego.

Alguien puede querer, como se ve comúnmente en algunos políticos, gobernar por decreto y confundir una sentencia con hechos. Aun cuando se crea que tienen las sentencias o las frases que denotan un deseo algún tipo de estatus ontológico, eso no significa que, efectivamente, exista un estado de cosas tales que correspondan a una realidad sentida o percibida en el mundo. Por eso, coincidimos en que las elecciones se hacen dentro de los parámetros de lo posible, técnica, lógica o empíricamente. Las elecciones que se hacen están dentro de los parámetros de lo posible, sin embargo, requiere de otro profundo análisis de la objetividad de la teoría de la elección del saber qué es lo que realmente es posible y lo que no es posible. Vgr. Si bien Leonardo DaVinci vislumbró la imagen de un helicóptero, imposible para su tiempo, ello no significó que esa idea no pudiera materializarse cuando las posibilidades técnicas lo permitieron siglos después.

Escoger entre lo posible significa, de manera inmediata, tomar una decisión u otra y que ambas, o más posibilidades, sean factibles de realizar. Vgr. Querer teletransportarse es una posibilidad de la literatura de ciencia ficción y mejor lograda en la cinematografía a través de efectos visuales, pero, en estricto sentido de lo que hay, no es posible hacerlo, aun cuando el deseo de la persona sea muy grande. Entonces, escoger genuinamente, significa escoger entre lo posible, dice el filósofo.

Si bien se puede desear lo imposible, la única elección auténtica se da sobre lo posible, Aristóteles da el ejemplo de desear ser inmortal (EN, 1112a 36), pero ello, no basta para poder ser posible. En este sentido, los deseos pueden no tener límites, dado que la imaginación tampoco los tiene. Algunos deseos pueden provenir de la imaginación y otros pueden provenir de ciertas necesidades fisiológicas. Los niveles de deseo varían en cantidad y cualidad. En cantidad porque puede ser un deseo moderado o un deseo intenso por obtener algo de que se carece, y calidad, en relación al tipo de deseo que se tenga. Puede ser, como ya hemos dicho básico, pero también puede ser de tipo psicológico como el prestigio, el amor, la realización del proyecto personal de vida.

\section{Elección y medios}

El deseo, dice Aristóteles, se refiere más bien al fin (EN, 1112a 11) y la elección a los medios para alcanzar dicho fin (EN 1111b 26-28). El deseo es alcanzar un estado de cosas, pero el camino que se tome para alcanzar ese estado de cosas, 
es producto de una elección. ${ }^{5}$ Los deseos pueden estar en algunas ocasiones por encima de los propios medios y, como se dijo antes, buscar alcanzar un estado de cosas que no sea posible, por múltiples factores, pero coincidimos en que la elección se basa en escoger cuáles serán los medios para alcanzar ese estado de cosas deseado. Ahora, la fuerza de ese deseo puede ser definitorio de que la persona dé el paso a esa acción, porque puede tener el deseo de hacer o alcanzar algo, pero no tener la voluntad suficiente para tomar acción en esa dirección.

Consideramos, sin embargo, que tampoco el deseo sea algo irracional o dado, pues aún el deseo de algo está en dos planos: tanto en el plano de lo consciente, de estarlo deseando en ese preciso momento y tomar consciencia de ello; como en el plano inconsciente -o irracional lo llamará Aristótelesde lo deseado. Sin embargo, nos parece que también el deseo forma parte de la elección pues, escogemos lo que queremos, no lo que no queremos y aún cuando en el fondo algo no se quiera, por sus resultados a largo plazo, de alguna manera, sí hay un proceso de toma de decisión de ese deseo.

Las ideas son eso, sólo ideas, pero que deben llevar a la acción para que se conviertan en algo tangible o realizable. Existe una decisión en el fondo del deseo, se desea desear o simplemente se decide no desear. Se puede también tomar la decisión de no desear algo porque se sabe que podría ese deseo tener consecuencias indeseables. Vgr. Pueden existir apetitos sexuales que sean inconfesables por no ser lícitos o, simplemente, socialmente inaceptables, pero ello no significa que no existan esos deseos, pero existe la elección, primero de tomar o no conciencia de esos deseos y, posteriormente, saber qué hacer o dejar de hacer con esos deseos. Puede quedar en el estatus de, digámoslo así, una ocurrencia y saber que se queda sólo en eso, y que no se tienen intenciones de continuar por esa senda, entonces existe realmente una elección.

Ahora, cuando se tiene el deseo suficiente y la voluntad de alcanzar un fin, se actúa o no se actúa. Entonces, y sólo entonces, se toma una decisión sobre los medios posibles para alcanzar dicho estado de cosas. "La elección parece referirse a lo que depende de nosotros" (1112a 32) dice Aristóteles, "pues lo que se hace impulsivamente en modo alguno parece hecho por elección" (1112a 35). Pero aún cuando existen deseos que no depende de la persona, el deseo podría depender de quererlo o no quererlo desear. No es entrar en un conflicto interno sobre el deseo.

Se habla de una cierta disposición para lo práctico que es diferente a la virtud moral, pero virtud al fin. La virtud moral es capaz de distinguir qué es lo más conveniente que debemos hacer, en cambio la prudencia, vista desde esta óptica, se refiere al discernimiento para la aplicación de la regla, esto es, el criterio que se equipara al uso de la regla.

\footnotetext{
${ }^{5}$ Sostenemos que incluso en el heroinómano, hay elección previa y no porque deseé ser dependiente al fármaco, sino que, por una voluntad confundida de los fines, busca una felicidad efímera que, en sentido aristotélico, no la es.
} 
Si la acción es adecuada, justa o recta, no se relaciona directamente con la prudencia, lo que sí le concierne es el criterio para saber qué es lo más adecuado moralmente con base en un criterio más general, esto es, la regla.

Especialmente la ciencia, e incluso la ley, tratan de encontrar respuestas en el ámbito de lo universal y, a partir de ello, resolver asuntos contingentes; en el caso de la moral, las respuestas no suelen ser únicas, pues, aunque exista la regla "de hacer el bien y evitar el mal", el hombre sabio es aquel capaz de utilizar la regla para resolver, a partir de su experiencia, lo que les es contingente. "La prudencia se mueve en el ámbito de lo contingente, o sea, de aquello que puede ser de otra manera de la que es" (EN, 1140b 27).

La vida virtuosa es la realización perfecta de la naturaleza humana. El uso adecuado de la libertad para fines que potencian las habilidades del alma. La virtud moral es capaz de fijarnos objetivos, pero no es la prudencia la que decide qué objetivos perseguir sino, simplemente, cómo es que debemos seguir el camino para alcanzar esos objetivos.

\section{5. $\Phi$ póvnoıs - phronēsis - prudencia}

Aristóteles en su obra De anima se refirió al alma como una entidad, como forma del cuerpo y acto primero de la existencia que hace posible la vida; él se refirió entonces a un alma intelectiva o intelectual que no estaba presente en los animales, y mucho menos en los vegetales, porque ellos carecían de un apetito superior hacia el entendimiento y tampoco tenían lo que llamaríamos voluntad; también ubicó un alma sensitiva o sensible en donde, tanto hombres como animales, comparten habilidades de percepción por los sentidos, apetitos inferiores que provienen del instinto, entre los que se distinguen no sólo los de la carne, como apetitos sexuales sino, como él mismo sugirió, la supervivencia, el hambre, la defensa; finalmente, definió al alma vegetativa que se encarga de las funciones básicas como alimentarse, reproducirse y crecer del mismo modo en el hombre, en los animales y en las plantas.

Un alma irracional (sensitiva y vegetativa) y un alma racional (intelectiva). A su vez, el alma intelectiva la dividió en dos: una es capaz de contemplar las cosas que son necesarias, como es el caso de la ciencia y, la otra, capaz de distinguir aquello que es contingente, esto es, aquello que requiere de la deliberación.

El alma se divide en dos partes: una racional y otra irracional. En la parte que está dotada de razón se distinguen la prudencia, la sagacidad, la sabiduría, la instrucción, la memoria y otras facultades de este género. En la parte irracional es donde se encuentra lo que llamamos virtudes: la templanza, la justicia, el valor y todas las demás virtudes morales que son dignas de estimación y de alabanza (GM, I, 5). 
A este último aspecto es que nos referiremos como prudencia, que podríamos definir sucintamente como el inteligir con rectitud. En cambio, en la Ética a Nicómaco define la virtud en otro sentido, como "aquella capacidad del ser humano para saber qué es lo que realmente le conviene como un bien o un mal intrínseco" (EN, 1140b 11). La prudencia es una virtud intelectual de la inteligencia práctica, capaz de deliberar y hacerlo de manera particular en aquello que es contingente.

Es difícil a veces distinguir entre lo que es la prudencia y la sabiduría, porque ésta última pareciera una guía para actuar de manera virtuosa y la prudencia es resultado o una muestra de la sabiduría y el ser prudente equivale a ser sabio. Sin embargo, se debe reiterar que en tanto las cosas son contingentes necesitan de la prudencia para poder ser resueltas, en tanto de las cosas que ameritan la aplicación de un juicio universal, requieren de la sabiduría.

Lo que Aristóteles trata de saber, primero, cuál es la naturaleza de aquellos hombres llamados prudentes, y quiere definir quiénes pueden tener ese calificativo, y responde que "son aquellos que, al parecer, son capaces de deliberar de manera conveniente, correcta, de qué es lo bueno y útil para ellos mismos, no en sentido particular como la salud o la fuerza, sino aquello que contribuye a su virtud y a su felicidad" (EN, 1140a 26), aunque las traducciones difieren, en conclusión, para vivir bien en general.

El bien supremo del hombre para Aristóteles no es un elemento trascendental, sino que está en el aquí y el ahora. La actualización de todas sus potencialidades. La razón práctica tiene como meta, precisamente, saber cómo coordinar esos elementos para un fin último y, si bien el hombre podría tener un fin trascedente, no escapa a su cotidianeidad. Toda agente obra por un fin, pero ese fin varía entre criatura y criatura (Cfr. EN, 1098a16-19). El ejercicio virtuoso, la eudemonía está aquí, es un bien racional que se aleja, como algunos suponen, únicamente del bien inmediato que pueden procurar los sentidos (aunque Aristóteles jamás los suprime) por eso, el hombre, en esa medida en que puede utilizar su razón práctica para distinguir aquello que lo lleva a la perfección y aquello que lo extravía, es más humano.

Es una disposición racional, verdadera y práctica que se esboza en la actuación hacia un fin. El fin de la producción es distinto de ella, aclara, en cambio las acciones tienen un resultado por sí mismas: "porque el objeto de la producción es siempre diferente de la cosa producida; por lo contrario, el objeto de la acción es siempre la acción misma, puesto que el fin que ella se propone puede ser únicamente el obrar bien" (EN, 1140b 21).

El principio de la acción moral, cualquiera que ella sea, es siempre la causa final en cuya vista nos determinamos a obrar. Pero este principio no aparece inmediatamente al juicio, cuando el placer y el dolor lo han alterado y corrompido; el espíritu no ve entonces que es un deber aplicar este principio, y arreglar según él su conducta entera y todos sus deseos; porque el 
vicio destruye en nosotros el principio moral activo. Es necesario reconocer, que la prudencia es esta cualidad que, guiada por la verdad y por la razón, determina nuestra conducta con respecto a las cosas que pueden ser buenas para el hombre (EN, 1140b).

El problema que surge, antes de Aristóteles, en la deliberación de la naturaleza del bien en sí. Una respuesta inmediata que podemos ofrecer es aquello que contribuye a la permanencia más allá de la supervivencia o sobrevivencia, el vivir bien en general, es paralelo a la idea de felicidad, esto es, para Aristóteles: la amistad, la salud y la posesión de bienes materiales y un poco de buena suerte, regalo de la buena fortuna. Sin embargo, en estricto sentido, para Aristóteles, la felicidad es el cumplimiento perfecto de la naturaleza humana (EN, 1098a).

Veamos ahora la relación que pudiera tener con el concepto medieval de la sindéresis.

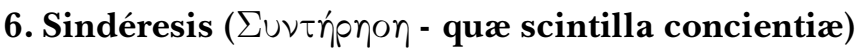

Una parte del texto de san Jerónimo Comentarios al Libro del Profeta Ezequiel introduce la división fundamental para la teoría sobre la sindéresis y la scintilla conscientiæ, y que la Escuela de París tradujo como scintilla rationis.

Jerónimo de Estridón en sus Comentarios (In Ez. 1-7) dividió el alma en cuatro partes: $\lambda o \gamma\llcorner x o ̀ v$, que se refiere a la ratio, lo racional, la parte lógica de nuestro cerebro, en este sentido alma es también mente y en la mente está el razonamiento. Después la $\Theta$ uuxòv, que ha sido traducida como ardor animositatis, la parte impetuosa del alma, la mente, del ánimo, el valor, el coraje, el

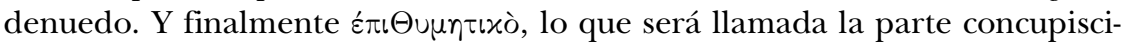
ble, en donde se alojan los apetitos, pero también la ambición, los sueños, la esperanza. Son las tres partes del alma que representa con un animal a cada

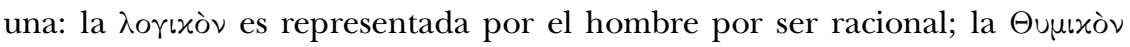

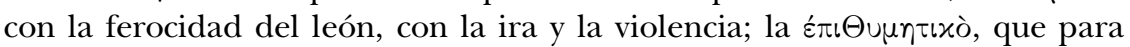
san Jerónimo es la lascivia, la lujuria, que ubica, como Galeno, en el hígado (jecore), y lo representa por un vitulo, un toro joven. Pero más allá "hay algo que no se contamina, ni se extingue y que, como el águila de san Juan, vuela por encima de las pasiones y de la razón del hombre: la outńpnov", que para los medievales será "el intelecto divino en el hombre".

La sindéresis no pertenece al ámbito de lo concupiscible, de lo irascible o de lo racional. Dice san Jerónimo que "no se mezcla con las otras tres sino que corrige a esas tres" y, aunque a veces parezca que se engaña por la razón, no significa que se equivoque, sino que es la conciencia la que con argumentos racionales da lugar al extravío.

En la tradición, hay continuidad del vocablo latino compuesto de los términos scintilla y conscientice, que conceptualmente son equivalentes a "luz de la 
razón" o "luz superior de la conciencia", como lo utiliza Pedro Lombardo en Los Cuatro Libros de Sentencias.

La palabra scintilla estuvo unida a concientia iniciando una larga discusión por definir si la sindéresis es una chispa de la conciencia, si se trata de un hábito natural de la razón práctica, una potencia o aquel esplendor brillante, splendore rutilantibus, que permite transitar entre lo terrenal y la dimensión óntica de la totalidad del ser. Para el historiador Odon Lottin, el concepto de scintilla conscientice entra en la terminología de la Escuela de París antes que la de sindéresis y asegura que el primero en referirse al término fue Anselmo de Laón, quien escribió un Sententiarum temprano. También refiere a Stephen Langton, Simón de Bisignano y a Felipe el Canciller, como los primeros tratadistas en retomar el problema de la sindéresis desde el siglo vi.

Sin embargo, es Alberto Magno quien adopta un nuevo enfoque intelectualista que habrá de proseguir santo Tomás de Aquino sobre la chispa de la conciencia. Para san Alberto la sindéresis es una fuerza especial del alma que tiene disposiciones universales respecto a las acciones y que el hombre no necesita aprender, sino que está escrita con antelación, por lo que el entendimiento práctico favorece al discernimiento profundo.

Este autor pone énfasis en que la sindéresis es una condición de la persona que medita y decide sobre sus actos, bajo la égida del "judicatorium o tribunal natural que no puede ser engañado porque pertenece a la ley natural y no a la Ley de los hombres". En la Summa de Creaturis se halla la solución a la Cuestión 71 Sobre la Sindéresis en que se pregunta san Alberto: "¿por qué fue puesta entre las partes del alma?"

San Alberto estudió el texto de san Jerónimo y hace una correlación entre la justicia, que "es el conocer el bien de manera natural", por lo que sostiene que no necesita una deducción. El razonamiento especulativo traza un puente hacia el entendimiento de las costumbres prácticas, aún por encima de los principios silogísticos y deductivos, y es una ciencia verdadera para todos. Para el autor bávaro, en el alma están sembradas semillas de justicia y de derecho, y siempre será recta si es justa. La justicia de los hombres es una creación, inventum que puede ser legal pero no siempre ética.

Para san Alberto la sindéresis es el sustrato antropológico de los primeros principios de la ley natural y ella proporciona las premisas mayores de la razón práctica. En cambio, la premisa menor se origina en las partes tanto superior como inferior del alma. En este sentido los juicios morales están expresados a través de un silogismo construido a partir de dos premisas: la mayor, se expresa por un principio universal que está facultado por la sindéresis, por ejemplo, "buscar el bien y evitar el mal"; la otra, la premisa menor relacionada con un acto específico, esto es, con la acción en sí, y la conclusión, que estará transmitida por el acto de la conciencia. La conciencia puede tomar una decisión, 
no así la ley natural a la que pertenece la sindéresis y que, por tanto, se dice que no se equivoca.

Para el filósofo de Lauingen, en la sindéresis está la ley natural como una potencia que contempla las ideas universales en iusnaturae. Por eso la llama "ley de la conciencia". No es gratuita la discusión para definir si la sindéresis es un hábito o una potencia, porque se coliga una serie de aspectos procesales en la decisión moral que hace cambiar de manera significativa el camino a través del cual se toman dichas determinaciones.

San Alberto acepta la definición de sindéresis que hiciera Felipe el Canciller como potentia cum habitu, pero explicó su infalibilidad mediante una idea aristotélica, intellectus semper verus aplicándolo al intelecto práctico o razón.

Por eso, siguiendo a Lottin podemos ver de qué modo es que las dos razones quedan insertas como partes de la causalidad eficiente y de la formal. La sindéresis es un hábito que proporciona los principios de la ley natural. La razón práctica puede discernir sobre el bien y el mal, del mismo modo que la inteligencia discierne entre lo verdadero y lo falso. Y refiere san Alberto a un regalo, un don que el hombre ha recibido en lo que en otros será la gratia. De acuerdo a esto, la sindéresis es un sustrato de los principios fundamentales de la ley natural.

Para Lottin, siguiendo a san Alberto del mismo modo en que en el orden especulativo hay principios fundamentales que ayudan a la inteligencia a discernir lo verdadero de lo falso, también en el orden práctico hay principios generales que permiten a la razón práctica discernir el bien del mal. En ambos órdenes, estas nociones fundamentales no son una adquisición de nuestra inteligencia, sino un don de la naturaleza o de la gracia. La sindéresis no es otra más que el substratum de esos principios fundamentales del derecho natural.

Así, relegada en las generalidades dice Lottin, la sindéresis se distingue de la conciencia de la cual es el destello. Es la sindéresis, en efecto, la que proporciona los principales argumentos a los razonamientos prácticos, de los cuales las conclusiones enuncian los juicios concretos que hacen objeto de la conciencia.

Ninguna otra criatura tiene esta dimensión; otras criaturas, debido a su naturaleza, actúan bajo instintos no-racionales y por lo tanto no equiparables a razonamientos éticos. El ser humano, en cambio, tiene varios aspectos que lo instauran como un ser que tiene albedrio y poder de decisión. En esto radica su constitución. Esta libre voluntad se manifiesta sólo en la introspección que está precedida por conocimiento. El hombre que ha adquirido elementos para realizar esa reflexión puede escoger en un haz de posibilidades cuáles son las acciones que va a realizar para alcanzar sus fines. Las ideas obtenidas se convierten en razones que pasan por un proceso deliberativo, que aun cuando parten de un conocimiento directo de las cosas, requieren de un principio de razón. 


\section{Conclusión}

Consideramos que no hay distinción en lo que es para el fin y del fin en el acto de la voluntad tanto Aristóteles como en los autores medievales. Pues aquello a lo que tiende la voluntad es un bien en sí mismo y para sí mismo. Su fin es lo que se hace. La voluntad tiene para su fin lo mismo que sí misma. Entre su acción y constitución no hay diferencia. Por eso se puede afirmar que la voluntad es el momento (decisión) de donde surge la acción; de ahí que afirmemos que es parte constitutiva de la razón práctica tanto en Aristóteles como en el medievo.

Incluso la voluntad tampoco actúa de la misma manera ante el bien y ante el mal. Santo Tomás llama voluntad al apetito en acto de bien. Al acto bueno lo llama voluntas y al acto malo noluntas, que no está asociado a la voluntad en acto de bien sino al apetito en acto de mal.

$\mathrm{El}$ agente se mueve pero no siempre lo hace con una dirección precisa, esto es, no siempre actúa con un fin determinado. Ahora bien, cuando actúa de manera voluntaria tiene primero el conocimiento de un fin y por tanto decide actuar, de modo tal que esos fines no sólo se persigan sino se cumplan. Así en la génesis del actuar por un fin determinado actúa voluntariamente y llama voluntarios aquellos actos que tienen un fin intrínseco y que se hacen por pura voluntad del sujeto.

No forzosamente el sujeto debe actuar en una dirección u otra, precisamente en ello radica la naturaleza de lo voluntario, ya que también está la posibilidad de no actuar, esto es, lo voluntario sin acción alguna como símbolo inequívoco de que lo voluntario opera sin contradicción en el dejar de actuar. La voluntad puede querer o no querer, y aún queriendo puede actuar o no actuar. De este modo el ámbito de acción, de voluntad y, sobre todo, de decisión en el sujeto, es muy amplio y depende exclusivamente de esa característica de lo voluntario que piensa, no piensa, actúa o no actúa, conforme a su deseo. En los cuatro casos actúa de manera interior o exterior; pero también el no actuar es un acto y todos ellos se ejercen en el ámbito de lo voluntario.

Más aún se puede conocer el fin y tener la voluntad de actuar hacia tal fin pero, además, se tiene la decisión de decidir cuánta energía se va a invertir para caminar hacia tal fin. En calidad se conoce la meta pero en cantidad de acciones se dispone de manera voluntaria la acción del sujeto. Podemos decidir hacer algo u obtener algo; en la decisión agregamos una acción y sobre la acción decidimos la cantidad de actos concretos que dispondremos para alcanzar tal fin. En ello se cuantifica la fuerza de la decisión voluntaria o como se dice comúnmente, la fortaleza de la decisión.

Aunque se hace la comparación con el entendimiento de los primeros principios del orden especulativo se debe tomar en consideración que, en el caso de los primeros principios del orden práctico, no se habla de otro tipo de entendimiento o razón, se trata de la misma razón enfocada a diversos objetos. 
No existe un salto de lo ontológico a lo moral, como quienes acusan la llamada falacia naturalista, sino que se trata de un hábito del intelecto, que, así como es capaz de captar las cosas particulares del entendimiento, del mismo modo es capaz de comprender y poner en práctica las cosas del orden práctico, entre las que se incluye la acción moral. Y si se considera que la intención está por encima de la voluntad o no forma parte de ella, podría ser que un acto que de suyo se considera como "malo" podría ser "bueno" en relación a su intención.

La elección puede ser la parte más importante del manejo de la voluntad y de la acción que ejerce la voluntad, previo razonamiento. Si bien la elección participa tanto de la voluntad como del entendimiento al parecer es más propensa a tomarse una decisión únicamente por el intelecto porque figura que toda decisión parte de una introspección racional, sin embargo, santo Tomás está consciente que en la realidad las elecciones se hacen, como suele decirse, tanto con la cabeza como con el corazón.

Si bien hay decisiones que son inmediatas y otras de mediano y largo plazo, tanto la prudencia como la sindéresis forman parte inherente a esos procesos de decisión, no en las decisiones inmediatas, sino en las decisiones de consecuencias a mediano y largo plazo.

Los medievales buscaron ir más allá de la frónesis. A diferencia de la sophia, la frónesis es la habilidad para pensar cómo y por qué se debe actuar para cambiar las cosas, especialmente para cambiar la vida propia. La acción es algo particular y en el caso del hombre, la sindéresis no basta para dirigirla, por ello se debe cultivar y practicar el hábito de la prudencia. La sindéresis determina los fines de las virtudes, les da el sentido último que las determina, pero el camino para aplicarlas depende de la virtud en general y de la aplicación particular. Determina qué virtud debe ser aplicada a cada caso particular, de acuerdo a las circunstancias que en ese momento se presenten a quien debe tomar dicha decisión ética.

\section{Referencias}

Albertus, 1896, Opera Omnia, Summa de Creaturis, Bibliopolam Editorem, París. Aquino, st. T., 2003, it Opúsculos y cuestiones selectas, De Veritate, Editorial Biblioteca Nueva, Madrid.

—, 2008, Comentario a las Sentencias de Pedro Lombardo, vol. II/2, Edición de Juan Cruz Cruz, Editorial Eunsa, Unav, Pamplona, España.

—, 2001, Suma de Teología, tomos I y iv, Edición dirigida por los Regentes de Estudios de las Provincias Dominicanas en España, coord. Damián Byrne, O.P., Biblioteca de Autores Cristianos, Madrid.

Aristóteles, 2002, Ética a Nicómaco, Edición Bilingüe y traducción de María Araujo y Julián Marías, Centro de Estudios Políticos y Constitucionales, Madrid. 
—, 1994, Acerca del Alma, Introducción, Traducción y Notas de Tomás Calvo Martínez, Editorial Gredos, España.

Dussel, E., 1973, Para una ética de la liberación latinoamericana. C. IV, Vol. 1, Siglo xxi Editores, Argentina.

Lottin, O., 1926, "Les premiers linéaments du Traité de la Syndérèse au moyen âge", en Revue néo-scolastique de philosophie, $28^{\circ}$ année, Deuxième série, Núm.12, pp. 422-454, doi: 10,3406/phlou, 1926. 